\title{
Phosphorus Placement for Annual Crops in the Tropics
}

By Luís Prochnow, Álvaro Resende, Adilson Junior, Eros Francisco, Valter Casarin, and Paulo Pavinato

P hosphorus interactions are complex in tropical soils. Many intense reactions take place that can prevent plant-available phosphate ions $\left(\mathrm{HPO}_{4}{ }^{2-}, \mathrm{H}_{2} \mathrm{PO}_{4}^{-}\right)$from reaching the crop. For example, ionic $\mathrm{P}$ can precipitate with $\mathrm{Ca}, \mathrm{Fe}$, and Al, be absorbed by microorganisms, or be adsorbed by soil colloids. Although generally taken up in lower amounts than other macronutrients (particularly $\mathrm{N}$ and $\mathrm{K}$ ), more $\mathrm{P}$ needs to be added to soils of the tropics than any other nutrient. Agriculture in tropical soils of low fertility have very limited chance of success without adequate use of $\mathrm{P}$ inputs.

Agronomic research has established recommendations for improving $\mathrm{P}$ fertilization in the tropics. For example, highly soluble $\mathrm{P}$ fertilizers such as SSP, TSP, MAP, and DAP perform better when applied in-furrow as granules to soils with $\mathrm{pH}$ values ranging between 6.0 to 6.5. Reactive phosphate rock works best in a more powdered form, well mixed with soils having $\mathrm{pH}$ values less than 5.4.

Recently, while looking for better operational efficiency, Brazilian farmers with large areas have been challenging the above recommendation for highly water soluble $\mathrm{P}$ sources and they are increasingly broadcasting these fertilizers on the soil surface before seeding. Equipment has been replaced, employees trained, and other operations adjusted with this goal in mind. Now a common question from farmers in Brazil is "Should I broadcast P?" or "Should I continue to broadcast P?" Often this question is asked with the hope for a positive reply. In reality, the answers to the questions farmers ask on this issue are more complicated than a simple "yes" or "no".

In fact, this matter can often bring intense debate between those in favor or against broadcasting $\mathrm{P}$ as both sides

This article discusses principles for optimizing the placement of $P$ in soils of the tropics-looking towards better agronomic, economic, environmental, and social outcomes. General guidelines are offered for short and long-term sustainability.

\section{KEYWORDS:}

broadcast; no-till; P placement; soluble P; runoff

\section{ABBREVIATIONS AND NOTES:}

$\mathrm{N}=$ nitrogen; $\mathrm{P}=$ phosphorus; $\mathrm{K}=$ potassium; $\mathrm{Ca}$ - calcium; $\mathrm{Fe}=$ iron; $\mathrm{Al}=$ aluminum; SSP = single superphosphate; TSP = triple superphosphate; $\mathrm{MAP}=$ monoammonium phosphate; $\mathrm{DAP}=$ diammonium phosphate; ppm = parts per million. present data proving their points. In the short-term point of view of many, noticeably farmers, applying broadcast $\mathrm{P}$ may be more favorable. However, a more ample and longterm view may indicate that the widespread use of this practice can lead to environmental problems. Such a broad view is not often the focus of those making field-level decisions, but it should be present in the minds of those responsible for planning agriculture at country level, guiding environmental stewardship, and even maintaining open channels to international markets.

\section{Agronomic Aspects About the Placement of Phosphorus}

Recommendations for the placement of soluble sources of $\mathrm{P}$ in tropical soils have always tried to minimize the contact of the fertilizer granule with the surface of soil particles as a means to improve efficiency. The low solubility of $\mathrm{P}$ compounds in the soil favors the recommendation to apply this $\mathrm{P}$ in close proximity to plant roots.

Two main strategies have been developed for P fertilization. The first, named corrective fertilization, has the goal to increase the soil $\mathrm{P}$ concentrations to near or above the critical value. This strategy can be very expensive for soils having high $\mathrm{P}$ fixation capacity because high rates of $\mathrm{P}$ fertilizer are required. The second more common approach is maintenance fertilization, which has the goal of nourishing each annual crop cycle. This approach uses lower rates applied in-furrow, is less expensive, but needs to be repeated each crop season. A third possibility involves a combination of both strategies by applying larger rates than required for maintenance fertilization, which increases the soil $\mathrm{P}$ concentration over time. In Brazil, there has never been a strategy recommending the surface broadcasting of soluble $\mathrm{P}$ at rates similar to a maintenance strategy. This ad-hoc approach has been created in the field specifically to optimize the operation of $\mathrm{P}$ application and facilitate more rapid planting of crops.

There is no general rule on how to place soluble sources of $\mathrm{P}$ in the soil. It is possible to obtain identical responses to either broadcast or in-furrow P. For farmers, or decision-makers at the field level, the first essential step is to understand the available $\mathrm{P}$ status throughout the whole soil profile. Gains due to more efficient farm field operations are always welcome, but they should not come at the expense of failing to consider a best practice for high yields and environmental protection. A good distribution of available $\mathrm{P}$ within the soil profile is important for such stability. As an example, Table 1 summarizes data for available soil $\mathrm{P}$ concentrations at different soil depths within three soil management scenarios $(\mathrm{A}=$ natural ecosystem, $\mathrm{B}=$ surface broad- 
Table 1. Availability of $P$ in three soil management scenarios $(A=$ natural ecosystem, B = P fertilizer applied on the soil surface, $\mathrm{C}=\mathrm{P}$ fertilizer applied in-furrow in a well-managed, no-till cropping system).

\begin{tabular}{clcc} 
& \multicolumn{3}{c}{ Management } \\
Soil depth, cm & A & B & C \\
\hline 0 to 5 & 3 & 65 & 48 \\
5 to 10 & 2 & 6 & 25 \\
10 to 20 & 1 & 2 & 19 \\
20 to 40 & 1 & 1 & 15 \\
40 to 60 & 1 & 1 & 2 \\
\hline
\end{tabular}

*Resin soil test $P$ categories: very low $=0$ to 6 , low $=7$ to 15 , medium $=16$ to 40 , high $=41$ to 80 , very high $\geq 80$.

cast $\mathrm{P}, \mathrm{C}=$ in-furrow $\mathrm{P}$ in a well-managed, no-till system). The better distribution of $\mathrm{P}$ observed in scenario $\mathrm{C}$ gives a better chance for the growth and development of plant roots compared to scenario A with very low soil $\mathrm{P}$ status, and scenario $\mathrm{B}$ with $\mathrm{P}$ concentrated at the soil surface. Scenarios $A$ and $B$ are also susceptible to periods of low water supply that dries the soil surface first. Thus, continuous broadcast application of $\mathrm{P}$ may also lead to water stress in dry years as roots mainly develop within the top soil layers.

\section{Environmental Aspects Related to the Placement of Phosphorus}

Agriculture in general and $\mathrm{P}$ fertilization in particular are among the factors influencing the eutrophication of waters, a concern for both environmentalists and society. Eutrophication of water happens by different means, with one important mode being field runoff of water containing some portion of applied $\mathrm{P}$ (inorganic or organic). Water eutrophication can also be sourced to the discharge of P-containing sewage sludge from urban areas. Organic sources like manure or compost are another main source of $\mathrm{P}$ entering streams and water bodies, especially in areas close to intensive livestock production. These areas can accumulate a lot of manure and farmers tend to apply it at high rates within a short radius of their origin.

If $\mathrm{P}$ fertilizers are broadcast, soluble and particulate $\mathrm{P}$ will accumulate at the soil surface leaving a larger portion susceptible to reaching water reservoirs through runoffeven in the Oxisols of the tropics. When applying $\mathrm{P}$ fertilizer in-furrow, the chance of $\mathrm{P}$ movement with runoff decreases significantly because it is incorporated deeper into the soil. Local research is always necessary to establish the potential risks of the different methods of $\mathrm{P}$ placement to runoff.

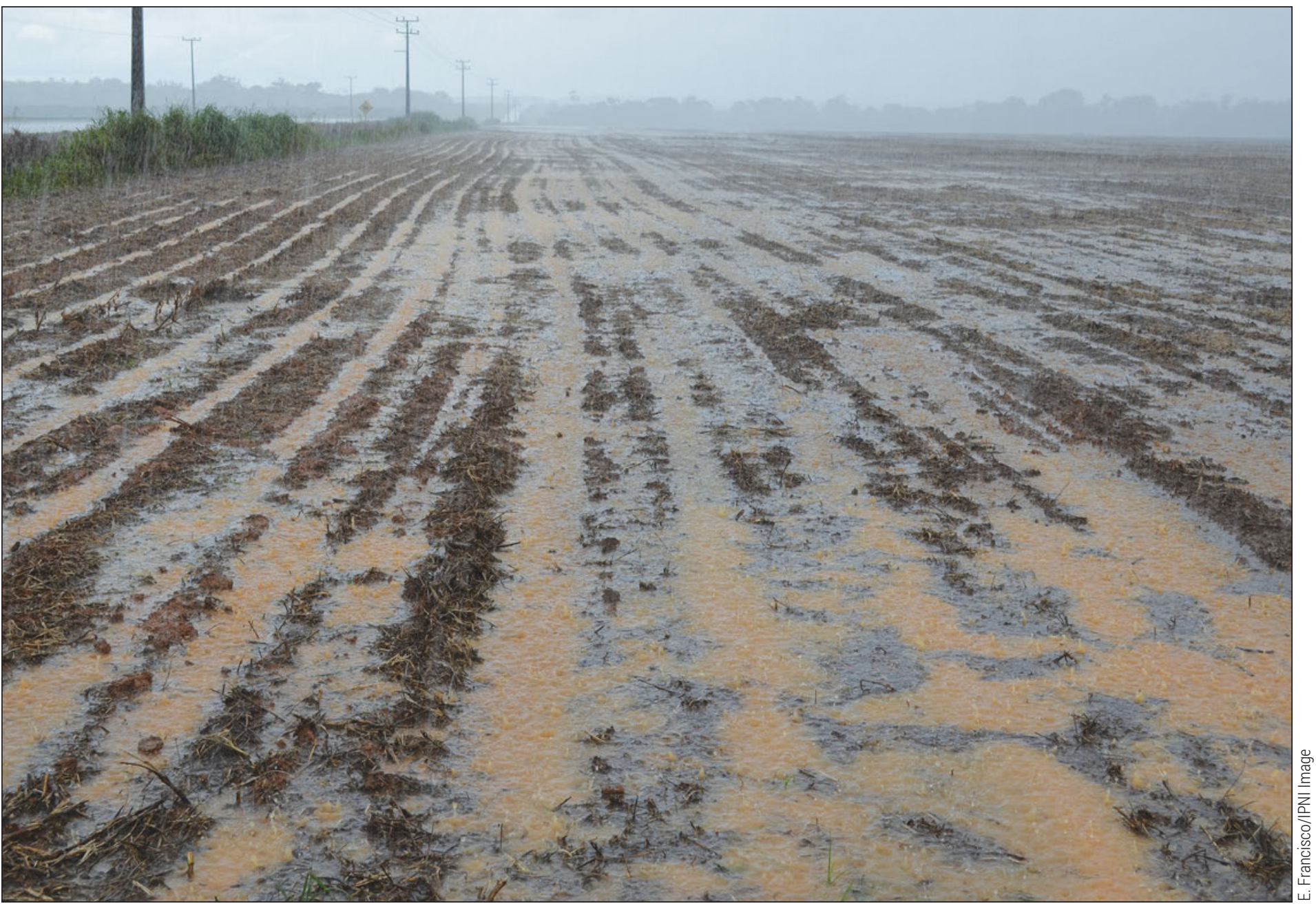

Runoff happens - even in the well-drained Oxisols of the tropics. 


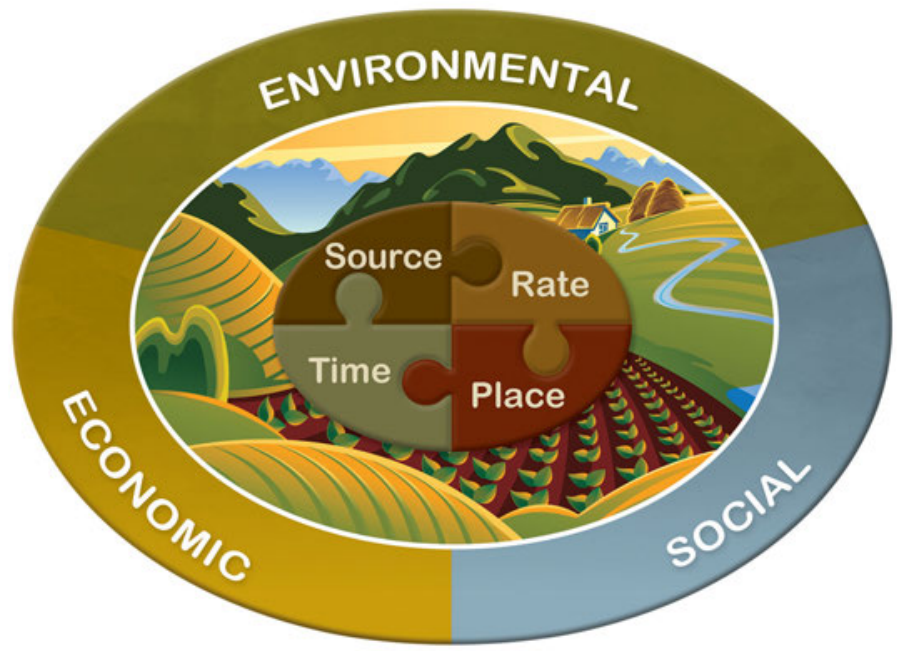

Phosphorus fertilization, as well as that of any other nutrient, should be based on the principles of 4R Nutrient Stewardship that can identify the right combination of source, rate, time, and place for each specific field (IPNI, 2016).

\section{Guidelines for the Placement of Phosphorus}

In the absence of local research that can help farmers establish best practice, some general guidelines on the placement of fertilizer $\mathrm{P}$ are provided below.

New areas - When opening new areas (still common in the tropics), if financial resources are available, farmers can choose to correct low soil $\mathrm{P}$ and raise it above the critical concentration. Fertilizer should be broadcasted and then incorporated into the soil. Although this strategy has a higher initial cost, it will create conditions suited for better crop establishment for a new no-till area due to deeper root distribution in the soil profile. In many cases this strategy is used initially, but it does not prevent the need for the maintenance rates of $\mathrm{P}$ application.

Increasing soil $\mathbf{P}$ with time - If the goal is to correct soil $\mathrm{P}$ concentrations gradually from very low or low to medium or high, farmers should apply $\mathrm{P}$ fertilizer at rates that are higher than crop removal. It is recommended to avoid broadcast applications and apply $\mathrm{P}$ fertilizer in-furrow. Farmers should soil test regularly in order to monitor the increase in the soil $\mathrm{P}$ concentration and understand when to decrease their application rates.

Soil topography - Soils with sloping topography have a higher potential for $\mathrm{P}$ loss by runoff so fertilizer should be applied in-furrow and not broadcasted.

Soil profiles with $\mathbf{P}$ stratification - In soils with moderate $\mathrm{P}$ concentrations at the surface $(0$ to $10 \mathrm{~cm})$ and very low or low soil $\mathrm{P}$ at 10 to $20 \mathrm{~cm}$, other factors such as soil topography and the possibility for water stress should be considered. Generally, the higher the risk for water stress and the more sloping the field landscape, the greater the requirement is to apply $\mathrm{P}$ fertilizer in-furrow and avoid broadcast applications.
Soil profiles without $\mathbf{P}$ stratification and with sufficient available $\mathbf{P}$ - In soils with moderate to high $\mathrm{P}$ concentrations to at least the 20-cm depth, and a field landscape that offers a low risk for runoff, $\mathrm{P}$ fertilizer may be broadcast on the soil surface if faster fertilization and seeding operations are desired.

Alternate the placement - Varying the $\mathrm{P}$ placement strategy over time can be a good way to combine the advantages of the different systems available.

Plan for in-furrow $\mathbf{P}$ placement - Modern, satellite-guided planting equipment is able to ensure optimal seed placement relative to where bands of fertilizer $\mathrm{P}$ are applied. When time allows, farmers should rely on this benefit and apply $\mathrm{P}$ in-furrow before seeding (i.e., the slower operation) and switch to faster options when time pressures change.

Pay close attention to spatial variability of $\mathbf{P}$ Phosphorus is a nutrient with high variability in the soil and soil $\mathrm{P}$ concentrations can vary greatly within short distances. Fields that have received $\mathrm{P}$ fertilizer for a number of years can have higher variability due to low $\mathrm{P}$ mobility in the soil and the resulting residual effect. Farmers should adjust application equipment so $\mathrm{P}$ distribution is uniform for both broadcast and more precise in-furrow systems. Correct adjustment of equipment may be even more important for broadcast fertilizer distribution due to differences in particle size amongst and within fertilizer products. Failure to account for this can create even higher variability in soil $\mathrm{P}$ concentrations.

Do no-till right - Cropping systems that have diverse crop rotations and which promote the accumulation of organic matter offer better conditions for water infiltration (Calonego et al., 2011; Moraes et al., 2016), which leads to protection against erosion and runoff. In Brazil, for example, about $50 \%$ of the area cultivated is done so under notill. Unfortunately, many fields still lack both adequate crop rotation and surface residue on the soil surface. If managed well, a variety of crops (and crop roots) under no-till favors $\mathrm{P}$ distribution throughout the soil profile through biological incorporation. Certain grasses have robust root systems that help to absorb P. One example of this effect is shown in

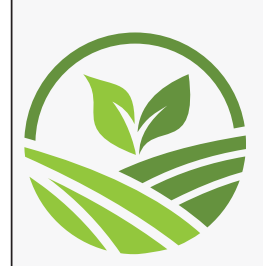

\section{TAKE IT TO THE FIELD}

1. Farmers should promote practices that increase the soil $P$ concentration throughout the profile and not just the surface.

2. In years with good water availability and P supply, expect little agronomic difference between broadcast or more localized P placements. Differences may only happen when the water supply is inadequate. 


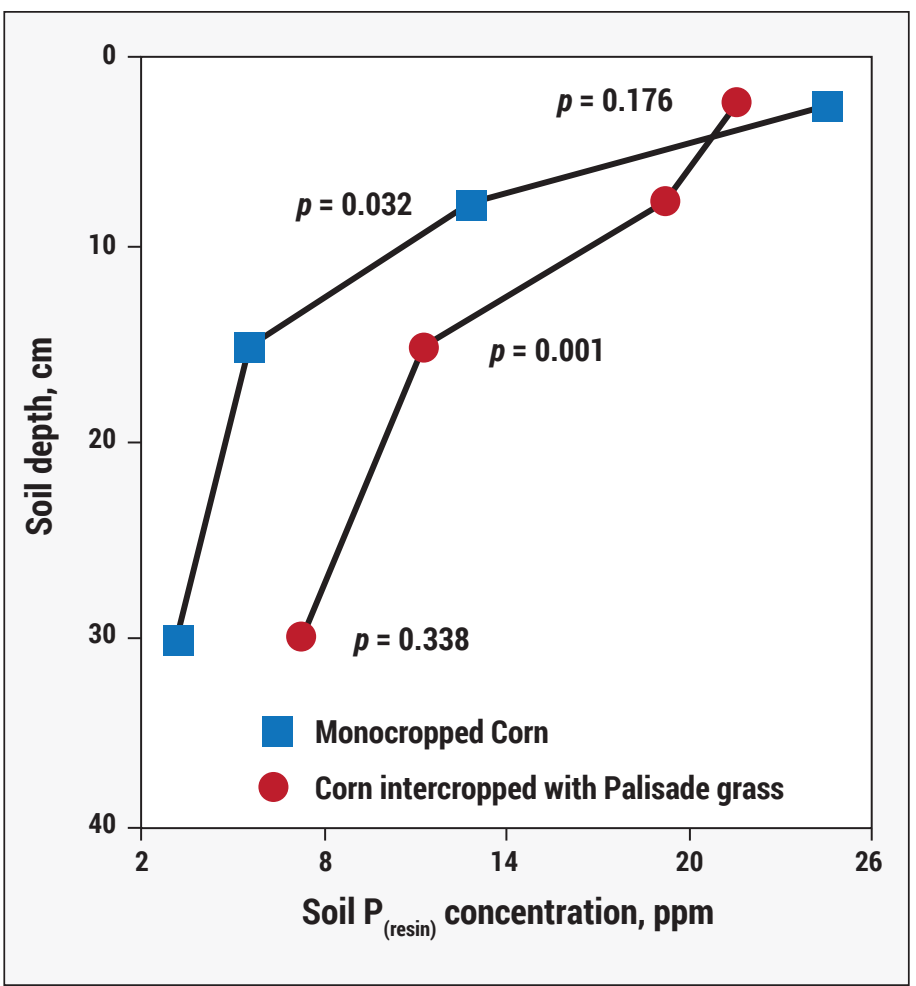

Figure 1. Farming systems including grasses may increase the soil $P$ through the soil profile in well-managed no-till systems. Source: Crusciol et al. 2015.

Figure 1 where available $\mathrm{P}$ increased between 5 to $40 \mathrm{~cm}$ when corn was intercropped with palisade grass (Urochloa brizantha), as opposed to monocropped corn (Crusciol et al., 2015). If poorly managed, no-till generally favors the stratification of $\mathrm{P}$ in the soil profile, which leads to much higher $\mathrm{P}$ concentrations at the soil surface.
Monitor the spatial distribution of soil fertility Evaluation of soil fertility at different soil depths (i.e., 0 to $10 \mathrm{~cm}$ and 10 to $20 \mathrm{~cm}$ ) helps to determine the best way to nourish crops. Phosphorus concentration and soil acidity are essential to monitor within the profile in order to decide which strategy for P placement should be used.

\section{Conclusions}

The 4R Nutrient Stewardship concept of applying the right source of fertilizer, at the right rate, time, and place is fundamental for optimizing yields, profit, and for protecting the environment. These general concepts should be adapted to each and every farm field. The right placement of $\mathrm{P}$ depends on several factors, as described in this article. Generalized approaches to $\mathrm{P}$ fertilization should be avoided on the farm. Decisions on whether $\mathrm{P}$ fertilizer placement should be in-furrow, more localized, broadcast at the soil surface, or a combination of these practices should be defined locally and according to principles described in this article. $\mathbf{B C}$

Dr. Prochnow is IPNI Brazil Program Director, Piracicaba, SP, Brazil; e-mail: Iprochnow@ipni.net.Dr. Resende is a researcher at Embrapa Maize and Sorghum, Sete Lagoas, MG. Dr. Oliveira is a researcher at Embrapa Soybean, Londrina, PR. Dr. Franciso is an IPNI Brazil Program Director and Dr. Casarin is a former IPNI Brazil Program Director, Piracicaba, SP. Dr. Pavinato is a professor at the University of São Paulo, Piracicaba, SP.

\section{References}

Calonego, J.C. et al. 2011. Rev. Bras. Ci. Solo. 35:2183-2190.

Crusciol, C.A.C. et al. 2015. Agron. J. 107:2271-2280.

IPNI. 2016. 4R Plant Nutrition Manual: A Manual for Improving the Management of Plant Nutrition, (Bruulsema, T.W. et al. eds.), International Plant Nutrition Institute, Peachtree Corners, GA, USA.

Moraes, M.T. et al. 2016. Soil and Tillage Res. 155:351-362. 